\title{
Drug Resistance and Genotypes of Strains of Mycobacterium tuberculosis Isolated from Human Immunodeficiency Virus- infected and Non-infected Tuberculosis Patients in Bauru, São Paulo, Brazil
}

\author{
Ida Maria Foschiani Dias Baptista, Maraníbia Cardoso Oelemann*, \\ Diltor Vladimir Araújo Opromolla, Philip Noel Suffys*/+
}

\author{
Equipe Técnica de Microbiologia, Divisão de Pesquisa e Ensino, Instituto Lauro de Souza Lima, Bauru, SP, Brasil \\ * Laboratório de Biologia Molecular e Diagnóstico de Doenças Infecciosas, Departamento de Bioquímica e Biologia Molecular, \\ Instituto Oswaldo Cruz-Fiocruz, Av. Brasil 4365, 21045-900 Rio de Janeiro, RJ, Brasil
}

\begin{abstract}
Little is known about transmission and drug resistance of tuberculosis (TB) in Bauru, State of São Paulo. The objective of this study was to evaluate risk factors for transmission of Mycobacterium tuberculosis strains in this area. Strains were collected from patients attended at ambulatory services in the region and susceptibility towards the main first line antibiotics was determined and fingerprinting performed. A total of 57 strains were submitted to susceptibility testing: 23 (42.6\%) were resistant to at least one drug while 3 (13\%) were resistant against both rifampicin and isoniazide. Resistant strains had been isolated from patients that had not $(n=13)$ or had $(n=9)$ previously been submitted to anti-TB treatment, demonstrating a preoccupying high level of primary resistance in the context of the study. All strains were submitted to IS6110 restriction fragment length polymorphism (IS6110RFLP) and double repetitive element PCR (DRE-PCR). Using IS6110-RFLP, 26.3\% of the strains were clustered and one cluster of 3 patients included 2 HIV-infected individuals that had been hospitalized together during 16 days; clustering of strains of patients from the hospital was however not higher than that of patients attended at health posts. According to DRE-PCR, 55.3\% belonged to a cluster, confirming the larger discriminatory power of IS6110RFLP when compared to DRE-PCR, that should therefore be used as a screening procedure only. No clinical, epidemiological or microbiological characteristics were associated with clustering so risk factors for transmission of TB could not be defined in the present study.
\end{abstract}

Key words: tuberculosis - transmission - drug resistance - fingerprinting - São Paulo - Brazil

Tuberculosis (TB) is still a calamity world wide and the main cause of death by a single infectious agent, namely Mycobacterium tuberculosis. The magnitude of the disease is associated with socio-economical level, spreading more easily in settings of agglomeration, mal nutrition and poverty, characteristics typical of third world nations (Gerhardt Filho \& Hijjar 1993, Raviglione et al. 1997, Lima et al. 1997). Two recent developments have worsened the TB pandemic: the increase of multi-drug resistant bacilli resulting from inadequate therapies and indiscriminate use of antibiotics, and Aids, rendering individuals more susceptible to development of TB.

In Brazil, over 50 million people are probably infected by $M$. tuberculosis and although 83,309 new TB cases have been notified in 1997, the real number of new cases/ year could be about 130,000. In the State of São Paulo, 18,266 new TB cases and an incidence of 55/100,000 were notified in 1995 (Brasil 1996). Few data exist on drug resistance in Brazil and general drug resistance in the State

This study was supported by CNPq, Papes and Pronex (661028/ 1998-4).

${ }^{+}$Corresponding author: Fax: +55-21-2270.9997. E-mail: psuffys@ioc.fiocruz.br

Received 30 January 2002

Accepted 21 October 2002 of São Paulo was reported to be $42.7 \%$ in 1992 (Silva et al. 1992); another survey determined primary resistance in that state during the nineties to be $16.5 \%$ and secondary resistance between $47.5 \%$ and $51.2 \%$ (Kritski et al. 1995).

The knowledge on the dynamics of TB transmission has recently improved thanks to the use of molecular typing techniques that allow the differentiation between $M$. tuberculosis strains. One of the most widely used genotyping techniques, restriction fragment length polymorphism (RFLP) based on the IS6110 insertion sequence (IS6110-RFLP), has been used to confirm TB outbreaks in hospitals and institutions for Aids patients, in asylums and prisons, to detect transmission of multi-drug resistant TB and to define risk factors associated with active transmission of TB in complex epidemiologic settings (Van Embden et al. 1993, Behr \& Small 1997, Cohn \& Obrien 1998, Fandinho et al. 2000). A PCR-based fingerprinting procedure, the double repetitive element PCR (DRE-PCR), amplifying fragments localized between IS6110 and the repetitive polymorphic sequence rich in GC (PGRS) has recently been developed and demonstrated a discriminatory capacity similar of smaller than IS6110-RFLP (Friedman et al. 1995, Montoro et al. 1998).

In this study, we evaluated the level of drug resistance in M. tuberculosis strains isolated from patients attended in Health Units of the city of Bauru, compared IS6110-RFLP and DRE-PCR fingerprinting and verified possible nosocomial transmission of TB in a hospital. 


\section{MATERIALS AND METHODS}

Study setting and patient population - A study was performed on 57 strains of $M$. tuberculosis collected from different patients during the period of May 1996 to May 1999, including 42 patients attended at the Hospital Manoel de Abreu (HMA), 2 at the health care of the Instituto Lauro de Souza Lima and 13 at Health Units in the region of Bauru, the later isolated at the Instituto Adolfo Lutz.

The HMA is a general hospital that attends TB cases from the State of São Paulo; the patients arrolled in the present study were all from the Bauru region. During the study period, the hospital had 3 adjacent rooms with a total of 13 beds for infectious disease patients (including Aids), while a single room with 6 beds was available for patients with pulmonary disease; the distance between the rooms was $50 \mathrm{~m}$.

Information on patient medical history and TB treatment were abstracted from medical charts and from a questionnaire containing additional demographic and epidemiological data. The study was approved by the ethical committee of the Medical Faculty of Botucatu, São Paulo.

Susceptibility testing - All clinical samples except a lymph node punction were of pulmonary origin and sent to the Laboratório de Micobactérias, Equipe Técnica de Microbiologia, Instituto Lauro de Souza Lima, for decontamination using the Petroff's method, culture in Lowenstein-Jensen medium (L-J) and identification by evaluation of biochemical characteristics (David et al. 1994). The samples from the Instituto Adolfo Lutz we received as cultures. The susceptibility test was performed on Lowenstein-Jensen medium using the standard proportion method of Canetti et al. (1963). Briefly, resistance was defined when at least $1 \%$ of the number of colonies present on drug-free medium was observed on medium containing $0.2 \mathrm{mg} / \mathrm{ml}$ of isoniazid (INH), $40 \mathrm{mg} / \mathrm{ml}$ for rifampin (RMP), $200 \mathrm{mg} / \mathrm{ml}$ for pyrazinamide (PZA), $2 \mathrm{mg} /$ $\mathrm{ml}$ for ethambutol (EMB) and $4 \mathrm{mg} / \mathrm{ml}$ for streptomycin (SM). Multi-drug resistance was defined as resistance to at least INH and RMP.

Genotyping by IS6110-RFLP and DRE-PCR - The M. tuberculosis strains were typed according to the standardized IS6110-RFLP method including internal marker in each sample as described by Van Embden et al. (1993). The RFLP profiles were analyzed and compared using GelCompar (Version 4.1; Applied Maths, Belgium), using the Dice coefficient of similarity and the UPGMA algorithm, and applying a $1.2 \%$ position tolerance. Only patterns with $100 \%$ similarity on the dendrogram that had been confirmed visually were considered as cluster. All strains were also submitted to DRE-PCR according to the methodology described in previous studies (Friedman et al. 1995, Montoro et al. 1998).

Statistical analysis - To verify whether there was a statistical significant association between strain clustering and any of the clinical, demographic, microbiological or epidemiologic data, the 2-squared test was used with $5 \%$ of significance.

\section{RESULTS}

Conventional analysis - The analysis of epidemiological and clinical characteristics of the 57 patients demonstrated that 34 patients had no previous history of TB of which 15 were HIV positive, $14 \mathrm{HIV}$ negative and 5 had no HIV information. Previous TB had occurred in 19 patients, 10 HIV positive, 5 HIV negative and 4 unknown; among these, 8 patients had discharge for cure and 10 patients abandoned the treatment. In 4 patients, presence or absence of previous tuberculosis could not be determined. All strains were identified as belonging to the $M$. tuberculosis complex and drug sensitivity testing could be performed in 54 isolates; 3 contaminated prior to testing. Thirty-one (57.4\%) of the strains were sensitive to all the drugs tested while 23 (42.6\%) strains were resistant to at least one drug (Table I). Of the 23 samples resistant to drugs, $13(56.5 \%)$ were isolated from patients with primary resistance and $8(34.8 \%)$ from patients that had been previously treated; $2(8.7 \%)$ strains were from patients with no information on previous treatment. Among the patients with resistant isolates, $14(61 \%$, including 6 with primary resistance, 6 with secondary resistance and 2 unknown) had been attended at the HMA, while $9(39 \%$, including 7 with primary resistance and 2 with secondary resistance) were from other Health Units; no statistically significant difference was observed between resistance levels at the hospital and other health units $(\mathrm{p}=0.07$; OR $=3.0$ ) or between primary and secondary resistance at these sites $(\mathrm{p}=0.37 ; \mathrm{OR}=0.29)$.

DNA fingerprinting analysis - Upon IS6110-RFLP analysis of the M. tuberculosis strains, IS6110 copy number varied from 3 to 17 and most had between 8 and 11 copies; only 1 strain had less than 6 IS6110 elements. A total of 46 different fingerprints were detected and 15 strains (26,3\%) belonged to 5 different clusters (Figure). Cluster I

\section{TABLE I}

Analysis of the resistance profile of the 23 Mycobacterium tuberculosis strains isolated from seropositive and seronegative patients in the region of Bauru, São Paulo, Brazil

\begin{tabular}{lcc}
\hline Drugs & Patients & $\%$ \\
\hline Resistance to one drug & 1 & 4.4 \\
INH & 7 & 30.5 \\
PZA & 6 & 26 \\
SM & 1 & 4.4 \\
Resistance to two drugs & 2 & 8.7 \\
PZA, SM & 1 & 4.4 \\
INH, SM & 1 & 4.4 \\
INH,PZA & & 4.4 \\
INH, EMB & 1 & 4.4 \\
Resistance to three drugs & & 8.7 \\
INH, SM, PZA & 1 & 100 \\
Multi-drug resistance & 2 & \\
INH, RMP, PZA & & \\
INH, RMP, PZA, EMB, SM & 23 & \\
\hline Total & &
\end{tabular}

INH: isoniazid, PZA: pyrazinamide, SM: streptomycin, RMP: rifampin, EMB: ethambutol 
(CI) comprised 3 strains from males of respectively 45,29 and 30 years old, living in Bauru and having been hospitalized in HMA, including two HIV-infected patients that had been hospitalized in the same room together during 16 days. One was diagnosed for TB and submitted to hospitalization while TB was diagnosed in the other patient during the stay at the hospital. Both patients had positive BAAR but no information on initiation of treatment could be recovered from the clinical files. Cluster II (CII) contains strains from 3 HIV-positive males of 31, 34 and 32 years old, living in Bauru and hospitalized in the HMA during different periods. Cluster III (CIII) is formed by 4 strains including from 2 HIV negative females of 30 and 25 years, and 2 males of 22 and 25 years old with no information on HIV status; the former were hospitalized in the HMA during different periods but no information on hospitalization is available for the latter. Cluster IV (CIV) contains 2 strains from HIVpositive males of 22 and 33 years and without epidemiological link. The last cluster (CV) contains strains from 3 female patients of 21 (HIV-negative), 34 (HIV-positive) and 44 years old (HIV unknown); two of them were hospitalized in the HMA during the same period while there was no information on the other. Table II demonstrates that there was no statistically significant association between any clinical, epidemiological or bacteriological parameter and strain clustering.

All strains were also submitted to DRE-PCR: 32 different profiles with 0 to 7 bands were observed, while 31

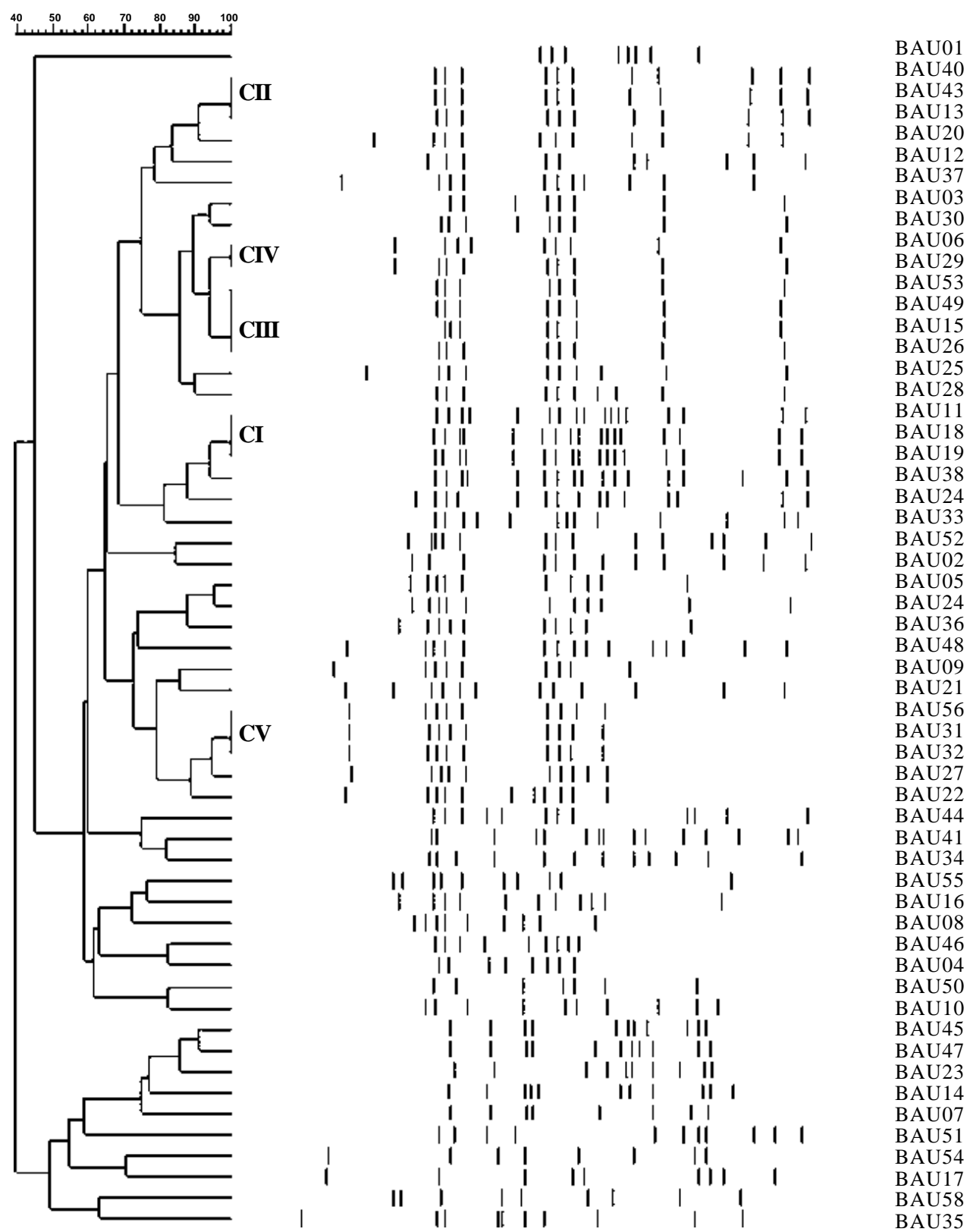

The dendrogram of the IS6110-restriction fragment length polymorphism patterns of 57 Mycobacterium tuberculosis strains was constructed using the Dice coefficient of similarity and the UPGMA algorithm using a position tolerance of $1.2 \%$. The Gophenetic correlation of dendrogram and similarity matrix was $87.9 \%$. Clusters CI, CII, CIII, CIV and CV are indicated on the dendrogram. 
TABLE II

Demographic, clinical and microbiological data of patients and strains and clustering frequency

\begin{tabular}{|c|c|c|c|}
\hline \multirow[b]{2}{*}{ Risk factor } & \multicolumn{2}{|c|}{ Number of patients } & \multirow[b]{2}{*}{ P value, Odds Ratio (CI, 95\%) } \\
\hline & Clustered & Non-clustered & \\
\hline \multicolumn{4}{|l|}{ Sex } \\
\hline Male & 38 & 10 & \\
\hline Female & 19 & 5 & $0.76,1.00(0.25-3.83)$ \\
\hline \multicolumn{4}{|l|}{ Age (years) } \\
\hline$<30$ & 16 & 4 & \\
\hline$>30$ & 41 & 11 & $1.00,1.07(0.26-4.71)$ \\
\hline \multicolumn{4}{|l|}{ Residence } \\
\hline House & 38 & 10 & \\
\hline Prison & 15 & 3 & \\
\hline Support Institution & 1 & 1 & \\
\hline Homeless & 2 & 0 & \\
\hline Unknown & 1 & 1 & 0.6 \\
\hline \multicolumn{4}{|l|}{ Diagnosis } \\
\hline Hospital & 30 & 12 & \\
\hline Others Health Units & 12 & 3 & $0.74,0.63(0.12-3.05)$ \\
\hline \multicolumn{4}{|l|}{ HIV Status } \\
\hline Positive & 26 & 9 & \\
\hline Negative & 22 & 3 & \\
\hline Unknown & 9 & 3 & 0.404 \\
\hline \multicolumn{4}{|l|}{ Previous tuberculosis } \\
\hline Yes & 19 & 8 & \\
\hline No & 33 & 5 & \\
\hline Unknown & 5 & 2 & 0.238 \\
\hline \multicolumn{4}{|l|}{ Resistance } \\
\hline Sensitive & 31 & 7 & \\
\hline Resistant to 1 drug & 14 & 5 & \\
\hline Resistant $\geq 2$ drugs & 9 & 2 & \\
\hline Unknown & 3 & 1 & 0.903 \\
\hline \multicolumn{4}{|l|}{ Type of resistance } \\
\hline Sensitive & 31 & 7 & \\
\hline Primary & 13 & 2 & \\
\hline Secondary & 8 & 5 & \\
\hline Unknown & 5 & 1 & 0.368 \\
\hline
\end{tabular}

strains belonged to 7 clusters. Cluster A contains 9 of the 12 strains with 1 band; cluster $\mathrm{B}$ and $\mathrm{C}$ contain respectively 4 and 3 of the 18 strains with 2 bands; cluster D contains 3 of the 15 strains with 3 bands; cluster E contains 3 of the 5 strains with 4 bands, cluster F contains all (4) strains with 5 bands and cluster G contains all (2) strains with 7 bands. The only strain that did not amplify neither did so after sample dilution. In order to evaluate reproducibility of the DRE-PCR, samples were submitted to two amplification reactions and in spite of the second one generated less PCR product, most of the strains demonstrated the same profile. Eleven strains demonstrated less bands after the second amplification but the position of the stronger bands was identical in all.

Upon comparing the two fingerprinting procedures, RFLP-IS6110 demonstrated a larger discriminatory capacity than DRE-PCR because strains with one or two band difference after RFLP-IS6110 had minor difference or identical profiles after DRE-PCR (Table III).

\section{DISCUSSION}

In Brazil, drug sensitivity testing of M. tuberculosis is not routinely performed but a small number of studies have shown a higher level of resistance in hospitals (Fandinho et al. 1999) when compared to the population attended in Health Units (Salem et al. 1990, Silva et al. 1992,). In spite of São Paulo and Rio de Janeiro being the most troublesome regions in respect to TB, little is known about the behavior of the disease in satellite regions such as Bauru, a city with more than 350.000 inhabitants. During the last 6 years, TB incidence in Bauru was about 50/ 100.000 and one study performed at the HMA and at the Faculdade de Medicina de Botucatu reported resistance levels of $17.5 \%$ (Correia 1998). The rate of drug resistance of $42.6 \%$ observed in the present study is 2.5 times higher, demonstrating the need of routine sensitivity testing of M. tuberculosis strains in the region of Bauru. Contrary to what is usually reported on resistance in Brazil (Kritski et al. 1995, Fandinho et al. 1999), the rate of primary resistance was higher than that of secondary resistance and could either be explained by a high level of transmission of resistant strains or to the lack of correct information about previous history of TB. The lower cluster frequency observed in isolates from patients with primary resistance when compared to those obtained from patients with secondary resistance however strongly indicates that the 
TABLE III

Comparison of the discriminatory power of IS6110-restriction fragment length polymorphism (RFLP) and double repetitive element-PCR (DRE)

\begin{tabular}{lc}
\hline $\begin{array}{l}\text { IS6110-RFLP } \\
\text { Cluster/no. strains/no. } \\
\text { of bands }\end{array}$ & $\begin{array}{c}\text { DRE-PCR } \\
\text { Cluster/no. of strains/no. } \\
\text { of bands }\end{array}$ \\
\hline $\mathrm{I} / 3 / 17$ & $\mathrm{D} / 6 / 3$ \\
$\mathrm{II} / 3 / 11$ & $\mathrm{~B} / 4 / 2$ \\
$\mathrm{III} / 4 / 8$ & $\mathrm{~A} / 9 / 1$ \\
$\mathrm{IV} / 2 / 11$ & $\mathrm{E} / 3 / 4$ \\
V/3/9 & $\mathrm{F} / 4 / 5$ \\
\hline
\end{tabular}

higher primary resistant level is not due to extensive transmission or outbreaks of resistant strains. One study performed by Monti et al. (1999) demonstrated a cure rate of $60 \%$ and treatment abandon of $14.1 \%$ in Bauru which could be partly responsible for the high resistance rates in the region.

The value of the IS6110-RFLP as an additional tool for epidemological studies of TB in Brazil has already been demonstrated (Suffys et al. 2000) and both IS6110 copy number and genetic polymorphism of the strains collected in the present study were high, confirming our earlier data. A clustering rate of $26.3 \%$ was observed, similar to the rate observed in hospitals and in the general population (Ivens de Araújo et al. 1998, Ferrazoli et al. 2000, Lourenço et al. 2000). Based on the hypothesis that strains belonging to a cluster are isolated from patients who are part of a recent transmission chain (Godfrey-Fausset 1999), in Bauru, higher level of recent transmission was not associated with sex, age, HIV status, previous TB, drug resistance, type of resistance, previous treatment and type of residence. Several studies have demonstrated that TB/ $\mathrm{HIV}$ co-infection and resistance to drugs are risk factors for development of TB (Edlin et al. 1992, Coronado et al. 1993, Small et al. 1993, Ivens de Araújo et al. 1998), as was also reported in a hospital in São Paulo (Ferrazoli et al. 2000) and in Rio de Janeiro (Fandinho et al. 2000). In these studies however, a considerable part of the circulating strains has been analyzed; in the present study, only one tenth of the $589 \mathrm{~TB}$ cases reported in the region of Bauru during the 3-year period (Secretaria Municipal de Saúde, pers. commun.) were submitted to strain typing. It has been shown that sampling influences cluster frequency (Glynn et al. 1999) and incomplete sampling is probably one of the reasons for lack of detection of risk factors for transmission. Nonetheless, combined analysis of patient and fingerprinting data was highly suggestive for transmission having occurred between two HIV patients who had been hospitalized together. These patients lived in different neighborhoods and apparently had no earlier social contact.

The largest cluster, CIII, was formed by strains with an 8 bands profile that has recently been described in a study that evaluated strains from of South and Southeast Brazil and is also observed in other countries; this pattern is characterizing a more easily spread strain or is more stable (Suffys et al. 2000). Although it is generally as- sumed that IS6110-RFLP clusters formed by patterns with less than 6 IS6110 copies should be confirmed by a secondary typing procedure, recent studies demonstrate the importance of confirmation also of certain high-copy IS6110-RFLP clusters (Wall et al. 1999, Gillespie et al. 2000, Niemann et al. 2000). In the present and a former study (Suffys et al. 2000), strains belonging to the CIII cluster had also identical DRE-PCR profile; in a recent fingerprinting study with strains from patients diagnosed at health care services in Rio de Janeiro however, differences were noted in DRE-PCR profiles obtained from strains with this IS6110-RFLP pattern, demonstrating the need of better characterization of these strains (Cardoso Oelemann et al. unpublished observation).

Reports on comparison of DRE-PCR with other molecular typing techniques describe either a low discriminatory power and poor reproducibility of the DRE-PCR when compared to other techniques, including IS6110RFLP (Sola et al. 1998, Kremer et al. 1999) or similar discriminatory power as RFLP (Montoro et al. 1998). Here, the PCR procedure had less discriminatory power than IS6110-RFLP, reflected by genetic polymorphism (respectively 32 and 46 patterns), cluster frequency (respectively $55.3 \%$ and $26.3 \%$ ) and concordance of both methodologies. Indeed, while all IS6110-RFLP clusters were confirmed by DRE-PCR, clusters constructed by the latter technique were larger and strains with one or two IS6110RFLP band difference sometimes belonged to a DRE-PCR cluster. The differences observed among different PCR reactions of the same strain were related to band intensity and difficult interpretation of these low intensity bands demands a rigorous control of the PCR conditions and use of controls to evaluate reproducibility between reactions.

\section{ACKNOWLEDGEMENTS}

To Dr José Roberto Pereira Lauris for statistical analysis.

\section{REFERENCES}

Behr MA, Small PM 1997. Molecular fingerprinting of Mycobacterium tuberculosis: How can it help the clinician? Clin Infect Dis 25: 806-810.

Brasil, Ministério da Saúde 1996. Tuberculose. http:// www.saúde.gov.br/programas e projetos/tuberculose.

Canetti G, Rist N, Grosset J 1963. Mesure de la sensibilité du bacille tuberculeux aux drogues antibacilaires par la méthode des proportions. Rev Tuberc Pneumol 27: 217-272.

Cohn DL, Obrien RJ 1998. The use of restriction fragment length polymorphism (RFLP) analysis for epidemiological studies of tuberculosis in developing countries. Int J Tuberc Lung Dis 2: 16-26.

Coronado VG, Beck-Sagué CM, Hutton MD, Davis BJ, Nicholas P, Villareal C, Woodley CL, Kilburn JO, Crawford JT, Frieden TR, Sinkowitz RL, Jarvis WR 1993. Transmission of multidrug-resistant Mycobacterium tuberculosis among persons with human immunodeficiency virus infection in an urban hospital: epidemiologic and restriction fragment length polymorphism analysis. J Infect Dis 168: 1052-1055.

Correia GN 1998. Diagnóstico Laboratorial da Tuberculose Pulmonar: Análise de Métodos Tradicionais Aplicados a Escarro de Pacientes sem Causa Básica Conhecida de Imunossupressão e de Doentes com Aids. Comparação do Padrão de Sensibilidade a Drogas das Cepas de Mycobac- 
terium Tuberculosis Isoladas, MSc Thesis, Faculdade de Medicina de Botucatu, Universidade Estadual Paulista, 75 pp.

David H, Brum L, Prieto E 1994. Manual de Micobacteriologia em Saúde Pública: Princípios e Métodos, Instituto de Higiene e Medicina Tropical, Lisboa, p. 49-73.

Edlin BR, Tokars JI, Grieco MH, Crawford JT, Williams J, Sordillo EM, Kenneth R, Kilburn JO, Dooley SW, Castro KG, Jarvis WR, Holmberg SD 1992. An outbreak of multidrug-resistant tuberculosis among hospitalized patients with the acquired immunodeficiency syndrome. $N$ Engl J Med 326: 1514-1521.

Fandinho FCO, Kritski AL, Hofer C, Conde Jr H, Ferreira RMC, Saad MHF, Silva MG, Riley LW, Fonseca LS 2000. RFLP patterns and risk factors for recent tuberculosis transmission among hospitalized tuberculosis patients in Rio de Janeiro, Brazil. Trans R Soc Trop Med Hyg 94: 271-275.

Fandinho FCO, Kritski AL, Hofer H, Conde Jr H, Ferreira RMC, Silva MG, Fonseca LS 1999. Drug resistance patterns among hospitalized tuberculosis patients in Rio de Janeiro, Brazil, 1993-1994. Mem Inst Oswaldo Cruz, 94: 543-547.

Ferrazoli L, Palaci M, Marques LRM, Jamal LF, Afiune JB, Chimara E, Martins MC, Telles MAS, Oliveira CFA, Palhares MC, Spada DTA, Riley LW 2000. Transmission of tuberculosis in an endemic urban setting in Brazil. Int $J$ Tuberc Lung Dis 4: 18-25.

Friedman CR, Stoeckle MY, Johnson Jr WD, Riley LW 1995. Double repetitive element PCR method for subtyping $M y$ cobacterium tuberculosis clinical isolates. J Clin Microbiol 33: 1383-1384.

Gerhardt Filho G, Hijjar MA 1993. Aspectos epidemiológicos da tuberculose no Brasil. J Pneumol 19: 4-10.

Gillespie SH, Dickens A, Mchugh TD 2000. False molecular clusters due to nonrandom association of IS6110 with $M y$ cobacterium tuberculosis. J Clin Microbiol 38: 2081-2086.

Glynn JR, Vynnycky E, Fine PEM 1999. Influence of sampling on estimates of clustering and recent transmission of $\mathrm{Myco-}$ bacterium tuberculosis derived from DNA fingerprinting techniques. Am J Epidemiol 149: 366-371.

Godfrey-Fausset P 1999. Interpretation of cluster studies of tuberculosis. Lancet 353: 427-428.

Ivens De Araújo ME, Fandinho FCO, Werneck-Barreto AM, Gonçalves-Veloso V, Grinstejn B, Lourenço MK, WerneckBarroso E, Degrave WM, Suffys PN 1998. DNA fingerprinting of Mycobacterium tuberculosis from patients with and without Aids in Rio de Janeiro. Bras J Med Biol Res 31: 369-372.

Kremer K, van Soolingen D, Frothingham R, Haas WH, Hermans PWM, Martin C, Palittapongarpim P, Plikaytis BB, Riley LW, Yakrus MA, Musser JM, van Embden JDA 1999. Comparison of methods based on different molecular epidemiological markers for typing of Mycobacterium tuberculosis complex strains: interlaboratory study of discriminatory power and reproducibility. J Clin Microbiol 37: 2607-2618.

Kritski AL, Dalcomo M, Del Bianco R, Melo FF, Pinto WP, Schechther M, Castelo A 1995. Associação tuberculose e infecção pelo HIV no Brasil. Bol Of Sanit Panam 118: 542554.
Lima M M, Belluomini M, Almeida MMMB, Arantes GR 1997. Co-infecção HIV/ tuberculose: necessidade de uma vigilância mais efetiva. Rev Saúde Publica 31: 217-220.

Lourenço MCS, Grinsztejn B, Fandinho FCO, Silva MG, Saad MHF, Fonseca LS 2000. Genotypic patterns of multiple isolates of M. tuberculosis from tuberculosis HIV patients. Trop Med Int Health 5: 488-494.

Monti JFC 1999. Perfil Epidemiológico, Clínico e Evolutivo da Tuberculose na Região de Bauru, MSc Thesis, Faculdade de Medicina de Botucatu, Universidade Estadual Paulista, $124 \mathrm{pp}$.

Montoro E, Valdivia J, Leão SC 1998. Molecular fingerprinting of Mycobacterium tuberculosis isolates obtained in Havana, Cuba, by IS6110 restriction fragment length polymorphism analysis and by the double repetitive element PCR method. J Clin Microbiol 36: 3099-3102.

Niemann S, Rusch-Gerdes S, Richter E, Thielen H, HeykesUden H, Diel R 2000. Stability of IS6110 restriction fragment length polymorphism patterns of Mycobacterium tuberculosis strains in actual chains of transmission. J Clin Microbiol 38: 2563-2567.

Raviglione, MC, Dye, C, Schmidt, S, Kochi, A 1997. WHO global surveillance and monitoring project. Assessment of worldwide tuberculosis control. Lancet 350: 624-629.

Salem JI, Goh KS, Litaiff LRL, Carcloso MSL, Briglia MFS 1990. An investigation of primary and acquired drugresistence of Mycobacterium tuberculosis in Manaus (Amazonas, Brazil). J Pneumol 16: 6-8.

Silva EAM, Sato DN, Telles, MAS, Martins MC, Palaci M, Ueki SYM 1992. Perfil de resistência de Mycobacterium tuberculosis no Estado de São Paulo, 1986 a 1990. Rev Inst Adolfo Lutz 52: 37-40.

Small PM, Shafer RW, Hopewell PC, Singh SP, Murphy MJ, Desmond E, Sierra MF, Schoolnik GK 1993. Exogenous reinfection with multidrug-resistant Mycobacterium tuberculosis in patients with advanced HIV infection. $N$ Engl $J$ Med 328: 1137-1144.

Sola CL, Horgen L, Maisetti J, Devallois A, Goh KS, Rastogi N 1998. Spoligotyping followed by double repetitive element PCR as rapid alternative to IS61 10 fingerprinting for epidemiological studies of tuberculosis. J Clin Microbiol 36: 11221124.

Suffys PN, Ivens De Araújo ME, Rossetti ML, Zaha A, Werneck-Barroso E, Werneck-Barreto AM, Campos E, van Soolingen D, Kremer K, Heersma H, Degrave WM 2000. Usefulness of IS6110-restriction fragment length polymorphism typing of Brazilian strain of Mycobacterium tuberculosis and comparison with an international fingerprint database. Res Microbiol 151: 343-351.

van Embden JDA, Cave MD, Crawford JT, Dale JW, Eisenach KD, Gicquel B, Hermans P, Martin C, McAdam R, Shinnick TM, Small PM 1993. Strain identification of Mycobacterium tuberculosis by DNA fingerprinting: recomendations for a standardized methodology. J Clin Microbiol 31: 406409.

Wall S, Kiran G, McFadden J, Dale JW 1999. Context-sensitive transposition of IS6110 in mycobacteria. Microbiology 145: 3169-3176. 